\title{
Are parental leaves considered as work interruptions by survey respondents? A methodological note ${ }^{1}$
}

\author{
Chaowen Chan \\ Department of Sociology, McGill University \\ chaowen.chan@mail.mcgill.ca
}

\author{
Dana Hamplová \\ Department of Sociology, Charles University (Czech Republic) \\ Institute of Sociology, ASCR
}

Céline Le Bourdais

Department of Sociology, McGill University

\begin{abstract}
Parental leaves and family-related work interruptions are linked to a variety of issues, such as children's well-being or women's work trajectories. Yet, the measurement of periods of absence from the labour market might be imprecise, especially in retrospective surveys. To evaluate the quality of the collected information, we examine whether women who reported taking a parental leave longer than six months also mentioned a corresponding work interruption, using the 2008 Living in Canada Survey (LCS) - Pilot. Our analysis shows that nearly half of women failed to do so. We investigate the sources of the discrepancy and suggest possible avenues of change for future surveys.
\end{abstract}

Keywords: Parental leave; work interruption; measurement; retrospective survey.

\section{Résumé}

La recherche a montré que les congés parentaux et les interruptions de travail pour raisons familiales ne sont pas sans effet sur le bien-être des enfants ou les trajectoires professionnelles des femmes. La mesure de ces périodes d'absence du marché du travail est cependant parfois imprécise, plus particulièrement dans les enquêtes rétrospectives. Pour évaluer la qualité de l'information recueillie, nous examinons si les femmes rejointes par l'enquête pilote Vivre au Canada qui ont rapporté avoir pris un congé parental de plus de six mois ont également mentionné avoir connu un arrêt de travail. L'analyse montre que près de la moitié des femmes ne l'ont pas fait. Nous analysons les sources des disparités observées et suggérons des pistes de changement pour les enquêtes futures. Mots-clés : congéparental, interruption de travail, instruments de mesure, enquête rétrospective.

1. A preliminary version of this paper was presented at the 2010 Annual Meeting of the Canadian Population Society. 


\section{Introduction}

A large body of research has shown that parental leaves and family-related work interruptions influence a variety of issues, such as children's well-being and development, women's work trajectories, or social inequality or poverty (Aisenbrey et al. 2009; Arranz et al. 2010; Han et al. 2009; Klerman and Leibowitz 1997; Li and Currie 1992; Zhang 2007). In spite of the important repercussions that work interruptions have on both parents' and their children's lives, only a few studies have examined the methodological issues related to collecting survey data on these interruptions. Yet, the measurement of previous periods of leave or absence from the labour market might be imprecise, especially in retrospective surveys that are often used to evaluate the long-term consequences of such interruptions on individuals' lives.

The standard practice employed by Statistics Canada in retrospective surveys, such as the General Social Survey (GSS) on family, is to ask currently and previously working respondents whether they had experienced a period during which they did not work or whether they were away from work for a given period of time (for changes and overview of the question see Chan et al. 2010). This approach usually assumes that work interruptions include parental leaves, in other words, that parents who took a parental leave also report a job interruption. However, Klerman and Leibowitz (1997) raise a number of questions linked to this assumption. They make a distinction between employment and work by arguing, for example, that individuals who are on paid or unpaid leaves are "employed but not at work." Because of the blurred distinction between these two concepts, parents might thus not necessarily associate parental leaves with job interruptions, especially if they received employer's compensation. Moreover, the definition and duration ofas well as the benefits linked to-parental leave vary with policy changes and, consequently, respondents might have difficulties over time in distinguishing between categories, such as "does not work," "job interruption," "unemployment" or "parental leave." Finally, a number of parents who took a parental leave do not eventually return to their previous job or, more generally, to any employed position. Those who do not return to the labour market experience an indefinite job interruption; when later interviewed in a retrospective survey collecting data on work histories, these respondents might not mention that their absence from work first began with a parental leave.

Given the complexities attached to the measurement of episodes spent out of employment or out of one's job, the goal of this research note is to evaluate the nature and quality of the information on work interruptions and parental leaves collected in retrospective surveys. To do so, we use the Living in Canada Survey (LCS) - Pilot that enables us to compare the responses on parental leaves and job interruptions provided by respondents in two separate sections of the questionnaire. Specifically, we examine whether respondents who reported taking a parental leave longer than six months 2 also mentioned a corresponding work interruption (i.e., job interruption starting in the same

2. Unfortunately, the data do not allow us to conduct the same comparison for parental leaves of shorter duration given that no information was collected in the survey on 6-month or shorter work interruptions. 
time frame) associated with caring for their own children. In addition, we try to identify some of the possible reasons that account for the discrepancy observed between the two sets of responses. We believe that the evaluation of the information collected in the pilot survey will be important not only for the development of the Living in Canada Survey, but also more broadly for the future cycles of the General Social Survey (GSS) on family from which the questions in the work history section were derived.

\section{Data}

The Living in Canada Survey - Pilot aimed to test the questionnaire of the first wave of the Canadian household panel survey that was developed by Statistics Canada and Human Resources and Skills Development Canada (Statistics Canada 2011). The original sample comprised nearly 4,000 respondents who were living in approximately 1,600 households selected in four Canadian provinces (New Brunswick, Quebec, Ontario, and Saskatchewan). The interviews took place between October and December of 2008. The LCS pilot gathered a vast array of information on households' and individuals' demographic, socioeconomic and health characteristics. It also collected the conjugal, parental, education and work retrospective histories of all household members aged 15 years and older (3,178 respondents).

Given the purpose of our study, it is important to note that the LCS pilot gathered information on parental leaves and job interruptions in two separate sections of the questionnaire. In a first section on parental trajectory, the survey recorded information on parental leave for all the biological, adopted, and step-children ${ }^{3}$ born after 1997 that respondents mentioned that they had given birth to or raised. Respondents were first asked if they took a parental leave for each of these children; if so, they were further asked about the duration (in months) of the leave, and whether or not they received any compensation from work or from the government during this leave.

In a further section of the questionnaire focusing on work history, respondents were asked if they had "ever worked at a business or a job for a period of at least six months," not counting summer jobs. Those who answered positively were then asked if there were "any periods longer than six months when (they) did not work at all," in which case the year and month of the beginning and end date of the "non-working period" were recorded. Each individual could report up to five non-working periods. In addition, respondents provided information about what was their "main activity during the non-working period."

It is important to note that the data are not representative of the Canadian population as a whole. The pilot was conducted only in four provinces and no weights are applied in the analyses, which might result in further biases. This paper thus does not provide a comprehensive study of the use of parental leave in Canada. Its goal is more modest and aims to compare different measurement instruments and their potential limitations.

3. The information on parental leave for adopted and step-children was collected only if the child joined the respondent's household before the age of one. 


\section{Results}

The analysis starts with a presentation of the data collected separately on work interruptions and parental leaves. Then follows a comparison of the answers provided by respondents to these two sets of questions which allows us to estimate the proportion of discordant answers. Finally, a logistic regression is used to explore the effect of socioeconomic and demographic characteristics that are possibly associated with the observed discrepancy. As only a very small number of men reported taking a parental leave or experiencing a family-related job interruption, only women are retained in the study. This approach has the advantage of including only one observation per child into the analysis. ${ }^{4}$

\section{Work interruptions}

Among the 1,250 women who mentioned that they had worked for a period of six months or longer, 642 or roughly 50 per cent reported that they had experienced at least one work interruption or "jobless spell" that lasted longer than six months. Altogether, these respondents experienced a total number of 1,012 work interruptions for which the information of the main type of activity is available. ${ }^{5}$ As Table 1 shows, home/family related activities are the most common reason invoked by women who had previously stopped working. Nearly two-thirds (66 per cent) of the jobless spells reported by women are centered around home/family related activities: for more than half (53 per cent) of the recorded work interruptions, women reported that their main activity consisted of caring for their children, and, in 13 per cent of cases of managing a home; for less than 20 per cent of jobless spells did women answer that they were either going to school (11 per cent) or looking for a job (8 per cent).

\section{Table 1. Main activity during all reported jobless spells.}

\begin{tabular}{lr}
\hline Type of main activity & $\%$ \\
\hline Family related activity & 13.4 \\
$\quad$ Managing a home & 52.3 \\
Caring for own children & \\
Studies and work related activity & 8.1 \\
$\quad$ Looking for a job/waiting for a recall & 10.9 \\
Going to school & 6.5 \\
Sick or disabled & 8.8 \\
Other activity & 100.0 \\
Total & 1,012 \\
\hline N & \\
Source: Statistics Canada, Living in Canada Survey (LCS) - Pilot, \\
2008.
\end{tabular}

4. Children living with their two parents were reported twice, given that both parents were interviewed separately on their parental history.

5. This number refers to all job interruptions reported by female respondents irrespective of whether the interruption occurred before or after 1997. 
A further examination of the type of activity conducted according to the rank $^{6}$ of the jobless spell shows that the category "caring for own children" accounts for a similar proportion of answers through the first three job interruptions-around 55 per cent (see Table 2); past this rank, the proportion decreases abruptly, which is not surprising given the level of fertility observed between 1998 and 2008. It should be noted that no direct reference to parental or maternity leave was made in the section on work history, either when asking whether the respondent stopped working for longer than six months or when providing examples of the types of main activity carried on during the jobless spell. However, we assume that many child-related job interruptions were in fact parental leaves.

Table 2. Proportion of jobless spells related to "Caring for own children"
according to the rank of the spell.

\begin{tabular}{lrrrr}
\hline & \multicolumn{3}{c}{ Rank of the spell } \\
\cline { 2 - 5 } & $1^{\text {st }}$ & $2^{\text {nd }}$ & $3^{\text {rd }}$ & $4^{\text {th }}+5^{\text {th }}$ \\
\hline All jobless spells & 539 & 218 & 78 & 30 \\
\% of jobless spells spent "caring for children" & 55.6 & 56.9 & 56.4 & 20.0 \\
\hline
\end{tabular}

Source: Statistics Canada, Living in Canada Survey (LCS) - Pilot, 2008.

${ }^{1}$ Excluding 147 cases with missing data on year at beginning or end of jobless spell.

\section{Parental leaves}

All respondents who reported a child born after 1997 in the parental history section of the questionnaire were asked if they had taken a parental leave following the birth of this child (or his or her arrival in their household) and, if so, for how many months. In total, 334 female respondents reported that they had given birth to, adopted or raised 528 children born after 1997 and who were living at home at the time of the survey. For nearly 65 per cent of these children, mothers stated that they took a parental leave (see Table 3). Close to two-thirds of these leaves were longer than six months; 25 per cent lasted six months or less, and for 11 per cent, mothers did not specify the duration. Parental leaves that lasted six months or less ( 83 children) as well as those of unspecified duration ${ }^{7}$ (36 children) had to be excluded from the analysis.

Table 3 shows little variation in the occurrence and duration of parental leave according to the rank of the child. ${ }^{8}$ Mothers reported taking a parental

6. The rank is determined by the date of occurrence.

7. These cases exhibit a high percentage of missing data in variables focusing on other aspects of family life (e.g., date of entry into the ongoing union). The observed pattern of missing data suggests that respondents were inclined to skip some questions of the interview, such as those focusing on children, when they knew that their married or cohabiting partner had already answered these questions. For more information, see Ménard et al. (2010).

8. One should note that the rank of the child is not directly linked to calendar years since we compare women who had different numbers of children who were born in different years. For example, the third child of a mother of three children born in 1998, 2000 and 2003 was older and born earlier than the first child of a mother of an only child born in 2005 . 


\begin{tabular}{|c|c|c|c|c|c|}
\hline \multirow{2}{*}{ Duration of the leave } & \multirow{2}{*}{$\begin{array}{c}1 \text { st child } \\
\%\end{array}$} & \multirow{2}{*}{$\begin{array}{c}2 \text { nd } \\
\%\end{array}$} & \multirow{2}{*}{$\begin{array}{c}3 \mathrm{rd}+ \\
\%\end{array}$} & \multicolumn{2}{|c|}{ Total } \\
\hline & & & & $\%$ & $\mathrm{~N}$ \\
\hline Equal to or longer than 7 months & 41.3 & 41.4 & 32.2 & 39.8 & 210 \\
\hline Less than 7 months & 15.0 & 15.2 & 18.9 & 15.7 & 83 \\
\hline Duration not reported & 9.2 & 7.1 & -2 & 6.8 & 36 \\
\hline No parental leave & 34.6 & 36.4 & 48.9 & 37.7 & 199 \\
\hline Total & 100.0 & 100.0 & 100.0 & 100.0 & \\
\hline $\mathrm{N}$ & 240 & 198 & 90 & & 528 \\
\hline
\end{tabular}

Source: Statistics Canada, Living in Canada Survey (LCS) - Pilot, 2008.

${ }^{1}$ Excluding 5 children who were not currently living at home at the time of the survey.

${ }^{2}$ Number too small to be released for confidentiality reason.

leave of seven months or longer for 41 per cent of first- and second-born children and a leave of shorter duration for 15 per cent of these children. For approximately a third of first- and second-born children (35 per cent and 36 per cent), they did not report taking any parental leave. The use of parental leave does, however, appear to decline among third and higher rank children. This might be a consequence of lower levels of employment among women who have three or more children.

\section{Comparing reports of parental leave and of work interruptions}

Our primary goal is to investigate whether parents who declared taking a parental leave also reported a corresponding work interruption. More specifically, we examine to what extent women who answered that they took a parental leave of at least seven months for a child born after 1997 reported a job interruption for "caring for own children" starting no more than one year apart from the birth of the child. ${ }^{9}$ We limit our comparison to parental leaves that began after respondents had been working at a business or a job for at least six months in order to exclude from the analysis mothers who were not asked questions about work interruptions around the birth of a child. Among the 210 children for whom mothers declared having taken a seven-month or longer parental leave, 192 (92 per cent) fulfilled this condition. Furthermore, we excluded all children born in 2008. At the time of the survey, the mothers of these children might have been granted a parental leave of a longer duration than six months but had not been absent from the labour market for a sufficiently long period to report a more than six months long work interruption. A total of 184 children are retained in the following analysis.

Only for 97 children (which represent 53 per cent of the 184 parental leaves) did parents mention that they had experienced a corresponding jobless spell to "care for their own children," which started within one year of the

9. Only the year (and not the month) in which jobless spells started and ended was collected in the pilot survey; it is thus impossible to establish with precision the duration in months elapsed between the birth of a child and the beginning of a jobless spell. 
child's birth (Table 4). When we take into account all work interruptions that began around the birth of a child, irrespective of the main activity conducted during the jobless spell, the number and proportion of matched answers increase slightly to 106 cases (58 per cent of the retained parental leaves); inconsistencies still exist for 78 cases. These results indicate a large amount of discrepancy in the answers provided by mothers in the work history section and in that focusing on parental history: almost half of parents who took parental leaves for at least seven months failed to report a corresponding work interruption that lasted longer than six months.

Table 4. Distribution of jobless spells according to main activity among observations of children for which mothers reported taking a parental leave of at least six months.

\begin{tabular}{lrrrr}
\hline Mothers reported a & \multicolumn{4}{c}{ Main activity during jobless spells } \\
\cline { 2 - 5 } corresponding jobless spell & Caring for children & \multicolumn{2}{c}{ Any activity } \\
\cline { 2 - 5 } & $\mathrm{N}$ & $\%$ & $\mathrm{~N}$ & $\%$ \\
Yes & 97 & 52.7 & 106 & 57.6 \\
No & 87 & 47.3 & 78 & 42.4 \\
\hline Total & 184 & 100.0 & 184 & 100.0 \\
\hline
\end{tabular}

Source: Statistics Canada, Living in Canada Survey (LCS) - Pilot, 2008.

What might be the main reasons explaining the lack of consistency observed between reports of parental leave and of work interruption for almost half the children for whom mothers report taking at least a seven-month parental leave? Table 5 shows that nearly three-quarters of cases concern children whose mothers failed to report any work interruption, assuming that they correctly reported the parental leave (71 per cent). One possible explanation could be that these mothers took a temporary leave for their new-born child from a job to which they later returned; they did not, therefore, consider this leave as a jobless or a non-working episode. Another relatively important source of discrepancy involves the timing of reported jobless spells. The beginning year of the non-working episode is more than one year apart from the birth of the child or is missing for 29 per cent of children.

Table 5. Types of reasons that account for the lack of consistency between parental leaves and jobless spells.

\begin{tabular}{lc}
\hline \multicolumn{1}{c}{ Type of reason } & $\%$ \\
\hline $\begin{array}{l}\text { Never reported a jobless spell } \\
\text { Reported a jobless spell, but did not specify the year or the }\end{array}$ & 70.5 \\
$\quad \begin{array}{l}\text { reported year was more than one year apart from the child's } \\
\text { birth }\end{array}$ & 29.5 \\
Total & 100.0 \\
\hline $\mathrm{N}$ & 78 \\
\hline
\end{tabular}

Source: Statistics Canada, Living in Canada Survey (LCS) - Pilot, 2008. 


\section{Who misreports?}

In this section, we attempt to identify some of the factors that can account for the discrepancies observed in respondents' reports of parental leaves and work interruptions. To do so, we use logistic regression to estimate the odds that mothers reported both a parental leave and a corresponding job interruption, no matter the type of activity conducted during the non-working episode, as opposed to not reporting-or misreporting the timing of - a job interruption (the reference category). This analysis is based on 180 children for whom mothers mentioned that they took a parental leave longer than six months and the information on the independent variables is available.

In a first step, we predict the odds of concordant reports according to a series of socio-demographic variables, which are measured at the time of survey or of the child's birth (the distribution of these variables is presented in the Appendix). The independent variables include: mother's highest educational degree completed at the survey, her age and conjugal status (married, cohabiting or not in a union) at the time of birth; the duration of the parental leave; as well as the time elapsed since birth (or age of the child at survey). Two times out of three, the mother was married and aged between 25 and 34 years at the time of birth (see the Appendix). The majority of parental leaves were taken for first- and second-born children (48 per cent and 38 per cent respectively), and two-thirds (67 per cent) of them lasted exactly 12 months. The reported parental leaves are spread quite evenly over the ten years preceding the survey; they are slightly more numerous in Quebec (32 per cent of the sample retained, compared to 19-26 per cent in the three other provinces).

We expected better educated mothers to be less likely to fail to report a work interruption or to misreport its timing. Our hypothesis is based on the assumption that women with higher education tend to be more career-oriented and therefore might be more aware of job interruptions. Similarly, we hypothesized that those who took a longer parental leave that began near the survey date would be less likely to misreport. However, the results of the logistic regression presented in Model 1 of Table 6 indicate that only the duration of the parental leave and mother's conjugal status at the time of birth significantly increase the odds (at the 0.10 level $^{10}$ ) of reporting a corresponding work interruption. The longer the duration of the parental leave, the more likely is the mother to report a job interruption. This finding is not surprising as women with shorter parental leaves might be less likely to perceive them as an interruption. The fact that single mothers at the time of birth are more likely to mention a corresponding work interruption might be a consequence of the financial strain they faced. It is possible that the decision to leave the work is felt more acutely in their case. The education variable and the time elapsed between the parental leave and the survey both affect in the expected direction the likelihood of reporting a work interruption, but none of them approach the 0.10 level of significance.

10. Given the small size of the sample retained for the analysis, we also comment on coefficients that reach the 0.10 level of significance. 
Table 6. Effect of various socio-demographic characteristics on the probability that mothers reported both a parental leave and a corresponding job interruption, as opposed to not reporting a job interruption or reporting one that is more than one year apart from the birth of the child. (Odds ratios from logistic regression)

\begin{tabular}{lrr}
\hline & Model 1 & Model 2 \\
\hline Child's gender (male) & 1.35 & 1.25 \\
Mother's age at birth of child & 0.96 & 0.97 \\
$\begin{array}{l}\text { Conjugal status at birth of child } \\
\text { (married) }\end{array}$ & 1.08 & 1.25 \\
$\quad$ Cohabiting & $2.93 \dagger$ & $3.50 \dagger$ \\
$\quad$ Not in union & 1.12 & 1.13 \\
Child's rank (1st) & 1.00 & 0.92 \\
$\quad$ 2nd & & \\
$\quad$ 3rd + & 0.63 & 0.41 \\
Education at survey (HS or less) & 1.78 & 1.75 \\
$\quad$ Some post-secondary education & 1.81 & 1.84 \\
$\quad$ College degree & 0.91 & 0.91 \\
$\quad$ University degree & $1.16 *$ & $1.16 \dagger$ \\
Years since birth of child & & 0.95 \\
Duration of parental leave (month) & & $5.66 * *$ \\
Province (Ontario) & & \\
$\quad$ New Brunswick & & \\
$\quad$ Quebec & & \\
$\quad$ Saskatchewan & & \\
\hline
\end{tabular}

Source: Statistics Canada, Living in Canada Survey (LCS) - Pilot, 2008.

${ }^{1}$ The reference categories are in parentheses.

Levels of significance: $* * * \mathrm{p}<0.001 ; * * \mathrm{p}<0.01 ; * \mathrm{p}<0.05 ; \dagger<0.10$.

In a second step, we included the province of interview in the analysis in order to control for differences that might be associated with interview related factors (such as the language used in the questionnaire and the interview) or with variations in parental leave benefits. ${ }^{11}$ The analysis shows clear differences across provinces in the odds that parents who reported taking at least a seven-month parental leave also mention a corresponding work interruption. Hence, mothers interviewed in the province of Saskatchewan are significantly more likely to do so than those living in Ontario, Quebec and New Brunswick (see Table 6); no significant difference separates the last three provinces, however. It is difficult to explain why respondents in Saskatchewan are less likely to give discrepant answers. It might be a consequence of interview-related differences or it might suggest that the meaning of "work" varies or is understood differently across the country.

11. For example, see Marshall (2010) who shows that working mothers in Quebec are more likely to benefit from employers' 'top-up' to the basic parental leave benefits. 


\section{Discussion and conclusion}

Our analysis has shown that roughly only half of mothers who mentioned taking a parental leave of at least seven months also reported a corresponding jobless episode when later asked about their work history in another section of the questionnaire. This high level discrepancy might have serious repercussions when analysing the effects of job interruptions on different aspects of individuals' lives using retrospective data. A detailed examination of the lack of consistency between the two sources of reports revealed that in nearly three-quarters of the cases ( 71 per cent), mothers who took a parental leave just did not mention experiencing a "non-working period." As suggested earlier, one possible explanation could be that these women received a financial compensation for the duration of the leave they took from a job to which they later returned and, thus, consequently did not consider this absence from the labour market as a non-working episode. Unfortunately, the LCS Pilot did not ask respondents whether they returned to the same job and performed duties similar to those they had prior to any period spent outside the labour market, be it a parental leave or a work interruption; it is thus impossible to verify the role of this factor in accounting for the observed lack of consistency. Another relatively important source of discrepancy concerned mothers who reported a jobless episode which started more than one year apart from the parental leave. The percentage of cases affected by misreporting the timing of the jobless episode could in fact be larger than that (29 per cent) observed here, given that only the year (and not the month) of the beginning and end dates of each episode was collected; this made it impossible to distinguish, in the case of jobless spells that were spread over two consecutive years, those that lasted one month and those that lasted 23 months. We were unable to conduct a similar analysis for shorter parental leaves as work interruptions of six months or less were not collected in the survey. However, we do not believe that the overall conclusions about the high level of discrepancies that we observed in this analysis would be significantly different for parental leaves of shorter duration.

The logistic regressions run to identify factors that can account for the discrepancies observed in mothers' reports of parental leave and work interruption did not reveal many strong statistical relations, which is in part due to the small size of the sample retained for the analysis. As expected, the likelihood that women who mentioned an at least seven-month long parental leave also reported a corresponding work interruption was shown to be positively linked to the duration of the parental leave. Furthermore, lone mothers at the time of birth were found to be more likely to report the job interruption. We also saw that the concordance of responses was significantly higher among female respondents interviewed in Saskatchewan than in any of the other three provinces, a result for which it is difficult to advance an explanation other than interview-related differences. The other socio-demographic variables did not appear to be significantly associated with the discrepancy. Even though the regression analysis might suggest that the observed pattern of responses is in part randomly distributed, we think that the amount of of the discrepancy 
should be considered seriously given that family and work related policies are often designed based on survey findings.

The fact that only half of women who mentioned taking a parental leave longer than six months also reported having stopped working for over than six months in the work history section raises serious questions about data collection and research on family and work. It does confirm the conceptual and methodological difficulties encountered when trying to distinguish between employment and work, a distinction that is probably not evident to respondents. Up to now, the approach taken in retrospective surveys for collecting standard employment histories might not correctly reflect individuals' work histories, particularly with regards to parental leave. A substantial proportion of mothers do not seem to consider parental leaves as "jobless" or "non-working" episodes. The formulation of a clear definition and the operationalization of the concepts of 'employment', 'work', and 'non-working period' or 'jobless spell' should thus be a priority for survey methodologists if we are to improve the reliability of employment histories in retrospective surveys. ${ }^{12}$

In retrospective surveys, collecting information on parental leaves within parental histories (i.e., when collecting information on each biological, adopted or step-child reported by respondents) most likely constitutes a better strategy to measure the use of parental leaves than doing so through work histories, because giving birth and raising children constitute significant events in respondents' lives. However, for this information to be useful in studies analysing the impact of parental leaves on individuals' and especially on mothers' future employment and income trajectories, it is imperative that data be collected on the nature of the participation (full-time/part-time) in the labour market at the beginning and end of the leave; in addition, information on whether individuals returned to the same job and performed duties similar to those they had prior to the parental leave is needed. In a context in which a growing proportion of parents, and especially of mothers, are taking parental leaves of longer duration, the need to collect complete detailed information on these leaves becomes crucial for policy development. Indeed, a previous study using the 1995 retrospective GSS on the family, the only GSS that collected information on whether respondents returned to their previous job following a non-working episode, showed the importance of this variable in accounting for the income disparities that mothers faced when compared to women who did not have children (Phipps et al. 2001).

In Canada, in the absence of a longitudinal panel survey that follows individuals as they experience family and work changes over the course of their life, the General Social Survey on family that retrospectively collects the respondents' employment and parental histories plays an essential role. However, in order for this survey to correctly assess the long term effects

12. The distinction between the terms 'employment' and 'work' is sometimes used indistinctively in surveys. For example, in the section of the 2006 GSS focussing on their main activity, respondents were asked: "For how many weeks during the past 12 months were you employed? (Include vacation ... and paternity/maternity leave)." But, when asked about their partner's main activity, the question read: "How many weeks did he/she work during the past 12 months? (Include all jobs; include vacation ... and paternity/maternity leave)." 
of family-related work interruptions on women's professional and income trajectories, some changes such as the ones suggested above, need to be introduced. The identification of such changes constituted the main goal of this research note.

\section{Acknowledgements}

Support for this research was provided by Statistics Canada and the Social Sciences and Humanities Research Council of Canada (SSHRC). Part of the research was conducted at the McGill Branch of the Quebec Inter-University Centre for Social Statistics (QICSS), which provides researchers with access to detailed survey data collected by Statistics Canada. The opinions expressed by the authors, however, are theirs alone. The authors thank the anonymous reviewers for their helpful comments.

\section{References}

Aisenbrey, S., M. Evertsson, and D. Grunow. 2009. Is there a career penalty for mothers' time out? A comparison of Germany, Sweden and the United States. Social Forces 88(2):573-605.

Arranz, J.M., C. García-Serrano, and M.A. Davia. 2010. Worker turnover and wages in Europe: The influence of unemployment and enactivity. The Manchester School 78(6):678-701.

Han, W.-J., C. Ruhm, and J. Waldfogel. 2009. Parental leave policies and parents' employment and leave-taking. Journal of Policy Analysis and Management 28(1):29-54.

Chan, C., D. Hamplová, and C. Le Bourdais. 2010. Are Parental Leaves Considered as Work Interruptions by Survey Respondents? A Methodological Note. Paper presented at the Annual Meeting of the Canadian Population Society. Montreal.

Klerman, J.A. and A.A. Leibowitz. 1997. Labour supply effects of state maternity leave legislation, in Gender and Family Issues in the Workplace, edited by F.D. Blau and R.G. Ehrenberg. New York: Sage, pp. 65-85.

Li, P.S. and D. Currie. 1992. Gender differences in work interruptions as unequal effects of marriage and childrearing: Findings from a Canadian national survey. Journal of Comparative Family Studies 23(2):217-29.

Marshall, K. 2010. Employer top-ups. Perspectives on Labour and Income 11(2):5-12.

Menard, F.-P., D. Hamplová, and C. Le Bourdais. 2010. Evaluation of the Measures of Parental Leave in the Living in Canada Survey (LCS) Pilot Data. Report submitted to Statistics Canada, March.

Phipps, S., P. Burton, and L. Lethbridge. 2001. In and out of the labour market: Long-term income consequences of child-related interruptions to women's paid work. The Canadian Journal of Economics 34(2): 411-29. 
Statistics Canada. 2011. Living in Canada. Ottawa (http://www.statcan.gc.ca/cgi$\mathrm{bin} / \mathrm{imdb} / \mathrm{p} 2 \mathrm{SV} \cdot \mathrm{pl}$ ? Function= getSurvey\&SDDS $=5144 \&$ lang $=\mathrm{en} \& \mathrm{db}=\mathrm{imdb}$ \&adm $=8 \&$ dis $=2$ ).

Zhang, X. 2007. Returning to the job after childbirth. Perspectives on Labour and Income 8(12):18-24. 
Appendix: Descriptive statistics (per cent or means) for the variables used in the logistic regression.

\begin{tabular}{|c|c|c|}
\hline \multicolumn{2}{|c|}{ Socio-demographic characteristics } & \multirow{2}{*}{$\frac{\begin{array}{r}\text { \% or } \\
\text { mean }\end{array}}{56.1}$} \\
\hline Child's gender (male) & Male & \\
\hline & Female & 43.9 \\
\hline \multirow[t]{5}{*}{ Parent's age at birth of child } & $18-24$ years & 13.9 \\
\hline & $25-29$ years & 30.0 \\
\hline & $30-34$ years & 34.4 \\
\hline & 35 years \& over & 21.7 \\
\hline & Mean age & 30.3 \\
\hline \multirow{3}{*}{$\begin{array}{l}\text { Conjugal status at birth of } \\
\text { child }\end{array}$} & Married & 66.2 \\
\hline & Cohabiting & 24.4 \\
\hline & Not in union & 9.4 \\
\hline \multirow[t]{3}{*}{ Child's rank } & $1 \mathrm{st}$ & 48.4 \\
\hline & $2 \mathrm{nd}$ & 38.3 \\
\hline & $3 \mathrm{rd} \&+$ & 13.3 \\
\hline \multirow{4}{*}{$\begin{array}{l}\text { Highest educational degree } \\
\text { achieved at survey }{ }^{1}\end{array}$} & High school or less & 16.1 \\
\hline & Some postsecondary educ. & 19.4 \\
\hline & College degree & 28.3 \\
\hline & University degree & 36.2 \\
\hline \multirow[t]{5}{*}{ Duration since birth of child } & $0-1$ year & 21.7 \\
\hline & $2-3$ years & 22.8 \\
\hline & 4-6 years & 34.4 \\
\hline & $7-10$ years & 21.1 \\
\hline & Mean duration & \\
\hline \multirow[t]{3}{*}{ Duration of parental leave } & 7-11 months & 23.9 \\
\hline & 12 months & 67.2 \\
\hline & More than 12 months & 8.9 \\
\hline \multirow[t]{4}{*}{ Province } & Ontario & 19.4 \\
\hline & New Brunswick & 25.6 \\
\hline & Quebec & 32.2 \\
\hline & Saskatchewan & 22.8 \\
\hline
\end{tabular}

Source: Statistics Canada, Living in Canada Survey (LCS) - Pilot, 2008.

${ }^{1}$ The category 'some postsecondary education' includes vocational or trade certificate; the category 'college degree' comprises university certificate. 